\title{
Agile Methodology In Offshore Outsourcing
}

Lisa-Anne G. Palmer, Pace University

James P. Lawler, (LawlerJ@pace.edu), Pace University

\begin{abstract}
Firms have to be cognizant of appropriate methods to deploy when managing offshore outsourcing. As industry continues to deploy agile methodology, such methodology may not be the best approach in offshore outsourcing. Managers may benefit from more disciplined application development methodologies. The case study examines risk factors of offshore outsourcing of software projects and the appropriateness of agile methodologies in these projects. The findings contribute important insight into the benefits and limitations of agile methods in offshore outsourcing.
\end{abstract}

\section{BACKGROUND}

$\mathrm{n}$ the current marketplace, application development projects are commonly off-shored to India, constituting $70 \%$ of outsourcing of software technology. Canada, China, Ireland, Israel, Philippines, and Russia are competitors to India in the off-shoring software market. Broadly defined, offshore outsourcing is the delegation of administrative, development, engineering, research, or support processes to a thirdparty organization in a lower-cost location [5] [16].

The application of low-cost labor in foreign countries began in the 1970s in firms in the manufacturing industry. In the 1990s, firms in the technology industry began to take advantage of this labor in application development and maintenance of projects, at a time of increased demand for technology skills, due partly to the Y2K bug and the outburst of the Internet. By the early 2000s, offshore outsourcing began to include other facets of technology, such as help desks and technical support.

Offshore outsourcing is affecting hundreds of firms and thousands of technology positions in the United States. Almost 104,000 positions have been moved offshore between 2000 and 2003, according to the Information Technology Association of America [9], and based on the Gartner Group, approximately one in ten technology positions is already performed offshore [14]. Benefits include the ability to staff software technology projects on an as-needed basis, avoiding down time for staff, and cost cutting.

Of these benefits, the driver for firms is to cut costs. However, firms have to consider offshore outsourcing not merely as an economic benefit, but as a complex initiative. Each facet of outsourcing has to be carefully evaluated and appropriately executed by firms. There is little margin for error.

This study analyzes an important facet of offshore outsourcing: application development. A project done in offshore outsourcing in a foreign organization is inherently different than a project done in-house in a domestic firm. Firms have to be cognizant of the distinction and apply the proper software development process to achieve project success.

There are ostensibly conflicting approaches to application development: disciplined methodologies and agile methodologies [2] [3]. Disciplined is driven by plans and requirements. A disciplined process is applied when there is an adherence to structure in terms of activities, artifacts, documents, roles and schedules, and the software is developed in strict adherence to the specifications. These methodologies introduce rigor and structure to a team and support specifically defined and standardized processes.

Agile is considered resilient to change, focused on simplicity, and cognizant of the difficulty of controlling software. An agile process is focused on smaller elements of tasks and emphasizes principles rather than processes. 
There is less rigor and structure imposed on a development team. Cycles of development are of short duration, and at the end of the cycles, priorities of the project are re-evaluated by the team. These methodologies frequently include Extreme Programming (XP), Test Driven Development, and Scrum [7] [8] [10] [11] [12] [17].

\section{INTRODUCTION}

Firms have focused on agility as they attempt to introduce methods to improve the application development of software systems, in environments where change is inevitable. The emergence of agile methodologies is introduced in the below Agile Manifesto [1].

We are uncovering better ways of developing software by doing it and helping others do it. Through this work we have come to value: Individuals and interactions over processes and tools, working software over comprehensive documentation, customer collaboration over contract negotiation, and responding to change over following a plan. That is, while there is value in the items on the right, we value the items on the left more.

Table1 lists characteristics inherent in agile methodologies.

Table 1: Characteristics of Agile Methodologies

\begin{tabular}{|l|l|l|}
\hline Agile Characteristic & Description & Source \\
\hline Continuous Integration & $\begin{array}{l}\text { Constant and iterative flow of programming and testing to identify } \\
\text { problems at early stages of project. }\end{array}$ & $\begin{array}{l}\text { Ambrose \& } \\
\text { Morello, 2004 [1] }\end{array}$ \\
\hline Embracing Change & $\begin{array}{l}\text { Change as an ally rather than an enemy; change allowing for creativity } \\
\text { and faster value to client; and changing requirements acceptable late in } \\
\text { development. }\end{array}$ & $\begin{array}{l}\text { Boehm \& } \\
\text { Turner, 2004 [2] }\end{array}$ \\
\hline $\begin{array}{l}\text { Fast Cycle / Frequent / } \\
\text { Iterative Delivery }\end{array}$ & $\begin{array}{l}\text { Having releases with short time spans; having implementation of only } \\
\text { priority releases; and having value to client faster. }\end{array}$ & \\
\hline Simple Design & $\begin{array}{l}\text { Evaluating designs to do only what is currently being developed, since } \\
\text { change is inevitable for future functions. }\end{array}$ & \\
\hline Re-Factoring & $\begin{array}{l}\text { Re-structuring of software to eliminate duplication, improve } \\
\text { communication, and simplify without changing behavior of software. }\end{array}$ & \\
\hline $\begin{array}{l}\text { Pair Programming / } \\
\text { Collaboration }\end{array}$ & $\begin{array}{l}\text { Style of development in which dual developers program jointly at one } \\
\text { computer on same design. }\end{array}$ & \\
\hline Retrospective & Post-iteration review of effectiveness of project methods. & Fowler, 2004 [6] \\
\hline Tacit / Implied Knowledge & $\begin{array}{l}\text { Providing project knowledge not in documentation but in minds of } \\
\text { developers. }\end{array}$ \\
\hline Test Driven Development & $\begin{array}{l}\text { Module testing by developers incrementally, providing short iteration } \\
\text { cycles. }\end{array}$ & $\begin{array}{l}\text { Providing input from staff of team, irrespective of management } \\
\text { positions. }\end{array}$ \\
\hline Autonomous Environment & &
\end{tabular}

Applying characteristics of agile methodologies to an offshore outsourcing initiative has to be considered a complex project, if coupled with the risk factors inherent in such a project.

Table 2 lists risk factors inherent in an offshore outsourcing project.

Table 2: Risk Factors of Offshore Outsourcing

\begin{tabular}{|l|l|}
\hline Factors & Source \\
\hline Culture & Sinha \& Terdiman, 2002 [18] \\
\hline Geographical Disbursement & Rae-Dupree, 2004 [14] \\
\hline Communication and Language & Sinha \& Terdiman, 2002 [18] \\
\hline Staff Turnover & Sinha \& Terdiman, 2002 [18] \\
\hline
\end{tabular}


Culture creates potential stress on offshore outsourcing projects that impacts success. Developers in India and the United States have diverse approaches to expectations. Those in the United States frequently overestimate efforts to complete a project, while those in India often underestimate the efforts and the impact of changes on a project.

Geographical disbursement and differences in staff shifts and time zones create increased difficulty on an offshore outsourcing project.

Language and communication create a critical impediment. If English is not the primary language in the country of the offshore outsourcing staff, communication is likely to be an issue. Even if English is the primary language, dissimilarity and miscomprehension of ideas, exacerbated by dialects, colloquialisms and interpretations, contribute to miscommunication [18].

Staff turnover is commonly experienced in offshore outsourcing. This issue necessitates the need for knowledge transfer from terminated staff to hired staff. Turnover of staff impacts the development and the maintenance of outsourcing projects.

In contrasting the above risk factors of offshore outsourcing to the aforementioned characteristics of agile methodologies, it is not definite if or how these methodologies can be applied to application development outsourcing. Offshore development could be contrary to agile development. Agile methodologies emphasize the importance of communication and language in software development and imply face-to-face dialogue in improving interaction.

Close geographic proximity is important in agile methodologies. Cultural dissimilarity and distant geographic proximity may preclude pair programming of the methodologies, relying instead on detailed documentation for indicating needs. Agile methodologies rely not on documentation but on implied knowledge of the software team.

Due to these concerns, firms may choose disciplined methodologies in managing offshore outsourcing. Flexibility in agile methodologies may be considered inappropriate in software outsourcing. Failure however to consider agile methodologies without further exploration may unreasonably contribute to highly costly and regimented processes, that may be slower in delivering and maintaining software systems of client firms.

\section{FOCUS OF STUDY}

The focus of this study is to explore in a preliminary survey and case study the appropriateness of agile methodologies in offshore outsourcing, by inclusion of the risk factors of outsourcing.

\section{METHODOLOGY}

The methodology of the study consists of two stages. Stage 1 includes a corporate information and literature survey of three leading software firms, Cognizant, ThoughtWorks and Valtech, which have applied agile methodologies in their application development offshore outsourcing projects. A five-point scale of 4-highly effective, 3-very effective, 2-effective, 1-slightly effective and 0-not effective is applied in the survey of the firms by one of the authors who is experienced in the software industry. Each firm was evaluated in effectiveness in managing risk factors of culture, geographic disbursement, communication and language, and staff turnover in agile methodologies. Stage 2 includes a case study of another leading software firm, Gemini Systems, which is applying agile development methodologies in its outsourcing projects. The case study was based on a detailed questionnaire furnished to key managers of the firm, and the questionnaire, which is based on Table I, is in the Appendix I of this study.

\section{Proposition}

Agile methodologies can be appropriate in the management of defined risk factors in offshore outsourcing of application development projects if included with disciplined methodologies. 


\section{SURVEY OF COGNIZANT, THOUGHTWORKS AND VALTECH}

Stage 1 of the study surveyed the firm information and practitioner literature on Cognizant, ThoughtWorks and Valtech, which are software firms that have applied agile development methodologies in their application development offshore outsourcing projects. Table 3 furnishes a profile of the firms.

Table 3: Profiles of Firms of Survey

\begin{tabular}{|c|c|c|c|}
\hline Firm & Offering & Offices & Offshore Outsourcing \\
\hline Cognizant & Application Development & $\begin{array}{l}\text { North America / United } \\
\text { Kingdom / Germany } \\
\text { Headquarters: New Jersey }\end{array}$ & India \\
\hline ThoughtWorks & $\begin{array}{l}\text { Application Development } \\
\text { and System Integration }\end{array}$ & $\begin{array}{l}\text { North America / United } \\
\text { Kingdom / Australia } \\
\text { Headquarters: Chicago }\end{array}$ & India \\
\hline Valtech & $\begin{array}{c}\text { Enterprise Application } \\
\text { Integration, Application } \\
\text { Development, and } \\
\text { Maintenance }\end{array}$ & $\begin{array}{l}\text { North America / Europe / } \\
\text { Asia } \\
\text { Headquarters: Paris, France }\end{array}$ & India \\
\hline
\end{tabular}

Cognizant bases its agile method on an industry Capability Maturity Model (CMM) Level 5 Light, but customizes the methodology in a disciplined SEI-CMM Level 5 Model [4] [13]. ThoughtWorks bases its methodology on an internal Distributed Agile Global Delivery Model, customized by the firm for international off-site projects. Valtech bases its agile methodology on an internal DuoShore Model, customized by the firm to include Extreme Programming (XP) and Unified Process (UP) [15].

These firms were evaluated for the effectiveness of their agile methodologies in mitigating offshore outsourcing risk factors of culture, geographical disbursement, language and communication, and staff turnover.

\section{Offshore Outsourcing Risk Factor: Culture}

Firm: Cognizant

Survey disclosed no evidence that Cognizant addressed culture risk in its application development outsourcing through agile methodology, and the firm is evaluated not effective in mitigating the risk.

Firm: ThoughtWorks

Survey disclosed evidence that ThoughtWorks focused on the development of autonomy among its developer staff, in order to mitigate culture risk. Firm invested however in autonomy and collaboration of teams. ThoughtWorks is evaluated very effective in mitigating culture risk in the application of an autonomous but collaborative environment.

\section{Firm: Valtech}

Survey indicated that Valtech hired a diversely educated and high number of local developer staff in multiple offshore locations in one country, in order to mitigate culture risk. Multiplicity of locations contributed to autonomy of the technical staff and to collaboration efforts, but not as facilitated as in ThoughtWorks. Valtech is evaluated effective in mitigating the culture risk. 


\section{Offshore Outsourcing Risk Factor: Geographical Disbursement}

Firm: Cognizant

Survey disclosed evidence that Cognizant included pair programming of software in local offshore offices. Software is programmed and tested in iterative stages in specific offices. Cognizant is evaluated effective in its efforts in mitigating the geographical disbursement risk

Firm: ThoughtWorks

Survey disclosed evidence that ThoughtWorks included continuous integration of software in the local offices. Continuous integration enables developers located in multiple offices to have correct and current software, regardless of geographical disbursement and location, and frequent iteration of the software enables faster delivery for client firms. ThoughtWorks is evaluated very effective in instituting continuous integration in mitigating geographical location risk.

Firm: Valtech

Survey indicated that Valtech included continuous integration of software, similar to ThoughtWorks. Valtech enhances integration with its Global Development Center (WDC) that furnishes a virtual 24x7 development environment. Valtech is very effective in mitigating geographical location risk.

\section{Offshore Outsourcing Risk Factor: Communication and Language}

Firm: Cognizant

Survey disclosed evidence that Cognizant generated extensive documents for its offshore offices, and because of its focus on documentation, Cognizant is evaluated not effective in mitigating communication risk in an agile methodology.

Firm: ThoughtWorks

Survey indicated that ThoughtWorks is focused not on structured documentation but on unstructured interaction enabled by conferencing, e-mail and instant messaging facilities of the World Wide Web. Developer staff teams further improve interaction in independent facilities locally. ThoughtWorks is evaluated highly effective in mitigating the language and communication risk.

\section{Firm: Valtech}

Survey indicated that Valtech is focused on structured and unstructured interaction, enabled by internal Intranet and external Internet facilities and platforms. Valtech is invested in knowledge management repositories. Valtech is very effective in mitigating the communication and language risk.

\section{Offshore Outsourcing Risk Factor: Staff Turnover}

\section{Firm: Cognizant}

Survey indicated that Cognizant follows a disciplined method in the documentation of software, in order to mitigate the impact of staff turnover, and is evaluated only slightly effective in mitigating turnover risk in an agile and implicit knowledge management methodology. 
Firm: ThoughtWorks

Survey indicated that ThoughtWorks follows a methodology similar to Cognizant, in not implementing implicit knowledge management systems, and is evaluated as only slightly effective in mitigating turnover in an agile methodology.

Firm: Valtech

Survey indicated that though Valtech is invested in knowledge management systems, the systems are unstructured, and Valtech is also evaluated as slightly effective in mitigating the turnover risk.

\section{Summary of Survey}

Table 4: Descriptive Summary - Survey*

\begin{tabular}{|l|c|c|c|c|c|}
\hline \multicolumn{1}{|c|}{ Company } & Culture & $\begin{array}{c}\text { Geographical } \\
\text { Disbursement }\end{array}$ & $\begin{array}{c}\text { Communication / } \\
\text { Language }\end{array}$ & Staff Turnover & Score \\
\hline Cognizant & 0 & 2 & 0 & 1 & 0.75 \\
\hline ThoughtWorks & 3 & 3 & 4 & 1 & 2.75 \\
\hline Valtech & 2 & 3 & 3 & 1 & 2.25 \\
\hline Average & 1.66 & 2.66 & 2.33 & 1.00 & 1.91 \\
\hline
\end{tabular}

* 4-Highly Effective, 3-Very Effective, 2-Effective, 1-Slightly Effective, 0-Not Effective

Table 4 indicates that ThoughtWorks is effective to potentially very effective (2.75) in implementing agile methods, in mitigating offshore outsourcing risk factors. Valtech is effective (2.25). Cognizant is not effective to slightly effective (0.75) in implementing the agile methodologies. Geographical disbursement (2.66) and communication and language (2.33) are more impacted by the agile methodologies, and culture (1.66) and turnover (1.00) less impacted by the methodologies. Importantly, none of the firms in the small sample of the survey fully implemented agile methodologies in offshore outsourcing, but included disciplined methods to mitigate the risk factors.

\section{CASE STUDY OF GEMINI SYSTEMS}

Stage 2 of the study was a case study of Gemini Systems, which is another leading software firm that is applying agile development methodologies in its application development offshore outsourcing projects. Its offerings are application development and enterprise application integration. It is headquartered in the United States, offices are in North America and the United States, and offshore outsourcing is in Russia, in the study. Three managers of the firm were independently surveyed for evaluation of the effectiveness of its agile methodology in mitigating offshore outsourcing risks of culture, geographical disbursement, communication and language, and staff turnover. The managers were surveyed by questionnaire, in Appendix I.

\section{Summary of Case Study}

Table 5: Descriptive Summary - Case Study*

\begin{tabular}{|l|c|c|c|c|c|}
\hline Manager & Culture & $\begin{array}{c}\text { Geographical } \\
\text { Disbursement }\end{array}$ & $\begin{array}{c}\text { Communication / } \\
\text { Language }\end{array}$ & Staff Turnover & Score \\
\hline Manager 1 & .75 & 2.62 & 1.87 & 2.00 & 1.81 \\
\hline Manager 2 & 1.25 & 3.00 & 2.50 & 1.33 & 2.02 \\
\hline Manager 3 & 1.00 & 2.50 & 1.87 & 2.33 & 1.92 \\
\hline Average & 1.00 & 2.70 & 2.08 & 1.88 & 1.91 \\
\hline
\end{tabular}

* 4-Highly Effective, 3-Very Effective, 2-Effective, 1-Slightly Effective, 0-Not Effective 
Table 5 indicates that the results of the small sample of managers in the case study noted that Gemini Systems is slightly effective to potentially effective (1.91) in implementing agile methodologies, in mitigating offshore outsourcing risk factors. Geographical disbursement (2.70) and communication and language (2.08) are more impacted by the methods, and culture (1.00) and turnover (1.88) less impacted by the methods. Results are similar to the survey, in that agile methods are perceived as more successful in mitigating geographical disbursement and language and communication risks, less successful in mitigating culture and turnover risks. Gemini Systems is further similar to Cognizant, ThoughtWorks and Valtech in not implementing full agile methodologies, but including disciplined methods to manage outsourcing risks. The proposition of the preliminary study that agile methods can be appropriate in the management of risk factors in offshore outsourcing of application development projects if included with disciplined methodologies is confirmed in the results of the case study and the literature survey.

\section{IMPLICATIONS OF STUDY}

The preliminary results of the study are helpful to managers considering agile methodologies in offshore outsourcing, because the results indicate the continued importance of disciplined methods. Managers considering agility in offshore outsourcing need to ascertain that the methodology is implemented appropriately. If agile methods are implemented inappropriately, the methods may be detrimental to project success. Factors of risk may be better managed in an integrated disciplined methodology. Finally, managers may benefit from further education in both the limitations of agile application development methods and the benefits of disciplined methodologies.

\section{LIMITATIONS AND OPPORTUNITIES IN RESEARCH}

Though this paper introduces a foundation for exploring agile methodologies in offshore outsourcing, inclusion of a larger firm sample and a larger manager sample is needed in a future research study. Further inclusion of risks not identified in the current analysis may be helpful in future study. Inclusion of other software firms having offices in less developed and more developed countries beyond India and Russia may be helpful in a new study.

\section{CONCLUSION}

This study indicates the importance of integrating agile application development methods and disciplined methods, in mitigating offshore outsourcing risks. Managers in industry need to be cognizant of the appropriateness of the features of the methods. Future planned research study of the methodologies will benefit the field.

\section{REFERENCES}

1. Ambrose, C. \& Morello, D. "Designing the Agile Organization: Design Principles and Practices". www.Gartner.com, 2004, January.

2. Boehm, B. \& Turner, R. "Balancing Agility and Discipline: A Guide for the Perplexed". Pearson Education, Inc, 2004.

3. Boehm, B. "Get Ready for Agile Methods with Care". www2.umassd.edu/swpi/xp/papers/r1064.pdf, 2002, January.

4. _ _Cognizant Builds and Manages GM Card Web Site Vauxhall Motors; Cognizant Is Extending the Relationship to GM Units Globally". www.findarticles.com, 2002, March.

5. Ferranti, M. "The Art of Successful Offshore Outsourcing". www.Computerweekly.com, 2004, June.

6. Fowler, M. "Using an Agile Software Process with Offshore Development". www.martinfowler.com, 2004, April.

7. Heller, M. "Would Agile Software Development Work in Your Shop?". www.cio.com, 2001, August.

8. Hoffman, T. "Information Technology Struggles to Become More Agile". www.computerworld.com, 2004, March.

9. Koch, C. "How to Outsource-Proof Your Information Technology Department". CIO Magazine, 2004, October.

10. Moore, S. \& Barnett, L. "Offshore Outsourcing and Agile Development”. Forrester Research, Inc., 2004, September. 
11. Morello, D. "Offshore Management Challenges Spur Information System Change in 2004". www.Gartner.com, 2003, November.

12. Overby, S. "One Outsources, the Other Does Not". CIO Magazine, 2004, November.

13. Narvenkar, H. "Cognizant's e-Business Process: Speed and Agility without Compromising Quality". www.cognizant.com, 2001, August.

14. Rae-Dupree, J. "Offshore Winds: Outsourcing”. www.cioinsight.com, 2004, April.

15. _ _ _Reduce Costs and Avoid New Risks. Improve Quality with Valtech DuoShore". www.Valtech.com, 2004, May.

16. Robinson, M. \& Kalakota, R. Offshore Outsourcing: Business Models, Return on Investment and Best Practices. Alpharetta, GA: Mivar Press, Inc, 2004.

17. Simons, M. "Internationally Agile". www.Informit.com, 2002, March.

18. Sinha, D. \& Terdiman, R. "Potential Risks in Offshore Sourcing". www.Gartner.com, 2002, September.

\section{APPENDIX}

\section{Questionnaire}

Manager

Objective of this questionnaire is to consider the appropriateness of application development agile methodologies in offshore outsourcing.

\section{Background Questions}

1. What is your name?

2. What is your length of employment at Gemini Systems?

3. What is your position at Gemini Systems?

4. What is your role at Gemini Systems?

5. What are your responsibilities?

6. Have you managed offshore outsourcing projects at Gemini Systems?

7. Have you managed offshore outsourcing projects with disciplined methodologies?

8. Have you managed offshore outsourcing projects with agile methodologies?

9. Please provide other information you would like to share about your background.

\section{Introduction Questions}

1. What disciplined methodology techniques have you used?

2. What agile methodology techniques have you used?

3. What have been the factors impacting use of disciplined or agile techniques?

Next set of questions will focus on culture as an offshore outsourcing risk. Please evaluate the effectiveness of the following techniques in mitigating culture risk.

\section{Culture Risk Questions}

1. Large amount of detailed documentation in order to mitigate the risk that the offshore staff may misinterpret your requirements.

4-Highly Effective

3-Very Effective

2-Effective

1-Slightly Effective

0-Not Effective 
2. Light documentation in order to mitigate the risk that the offshore staff may misinterpret your requirements.
4-Highly Effective
3-Very Effective
2-Effective
1-Slightly Effective
0-Not Effective

3. No documentation but oral communication in order to mitigate the risk that the offshore staff may misinterpret your requirements.

4-Highly Effective

3-Very Effective

2-Effective

1-Slightly Effective

0-Not Effective

4. Autonomous development environment among members of offshore staff.

4-Highly Effective

3-Very Effective

2-Effective

1-Slightly Effective

0-Not Effective

5. Additional comments regarding culture risk in offshore outsourcing?

Next set of questions will focus on geographic disbursement as an offshore outsourcing risk. Please evaluate the effectiveness of the following techniques in mitigating geographic disbursement risk.

\section{Geographic Disbursement Risk Questions}

1. Use of overlap in development hours of offshore staff in order to function effectively as a team.
4-Highly Effective
3-Very Effective
2-Effective
1-Slightly Effective
0-Not Effective

2. Functioning in longer hours using staff shifts with geographically disbursed offshore teams.
4-Highly Effective
3-Very Effective
2-Effective
1-Slightly Effective
0-Not Effective

3. Increasing interaction of geographically disbursed offshore teams.

4-Highly Effective

3-Very Effective

2-Effective 
1-Slightly Effective

0-Not Effective

4. Pair programming of geographically disbursed offshore teams.

4-Highly Effective

3-Very Effective

2-Effective

1-Slightly Effective

0-Not Effective

5. Iterative development cycles of projects of geographically disbursed offshore teams.

4-Highly Effective

3-Very Effective

2-Effective

1-Slightly Effective

0-Not Effective

6. One-week iterations of projects of geographically disbursed offshore teams.
4-Highly Effective
3-Very Effective
2-Effective
1-Slightly Effective
0-Not Effective

7. Two to three week iterations of projects of geographically disbursed offshore teams.

4-Highly Effective

3-Very Effective

2-Effective

1-Slightly Effective

0-Not Effective

8. Continuous code integration of geographically disbursed development offshore teams.

4-Highly Effective

3-Very Effective

2-Effective

1-Slightly Effective

0-Not Effective

9. Additional comments regarding geographic disbursement risk in offshore outsourcing?

Next set of questions will focus on language and communication as offshore outsourcing risks. Please evaluate the effectiveness of the following techniques in mitigating communication and language risk.

Communication and Language Risk Questions

1. Large amount of detailed documentation in order to communicate effectively to offshore teams. 4-Highly Effective

3-Very Effective 
2-Effective

1-Slightly Effective

0-Not Effective

2. Implementation of collaborative tools to mimic face-to-face communication between staff of offshore teams.

4-Highly Effective

3-Very Effective

2-Effective

1-Slightly Effective

0-Not Effective

3. Inclusion of home office staff in local office offshore teams and inclusion of local office offshore staff in home office staff teams.

4-Highly Effective

3-Very Effective

2-Effective

1-Slightly Effective

0 -Not Effective

4. Light documentation furnished to offshore staff teams.

4-Highly Effective

3-Very Effective

2-Effective

1-Slightly Effective

0-Not Effective

5. No documentation furnished to offshore staff teams.

4-Highly Effective

3-Very Effective

2-Effective

1-Slightly Effective

0-Not Effective

6. Iterative development cycle of projects of offshore teams.

4-Highly Effective

3-Very Effective

2-Effective

1-Slightly Effective

0-Not Effective

7. One-week iterations of projects of offshore teams.

4-Highly Effective

3-Very Effective

2-Effective

1-Slightly Effective

0-Not Effective 
8. Two to three week iterations of projects of offshore teams.
4-Highly Effective
3-Very Effective
2-Effective
1-Slightly Effective
0-Not Effective

9. Additional comments regarding language and communication risk in offshore outsourcing?

Next set of questions will focus on staff turnover as an offshore outsourcing risk. Please evaluate the effectiveness of the following techniques in mitigating staff turnover risk.

\section{Staff Turnover Risk Questions}

1. Use of detailed documentation on projects to enable knowledge transfer to new staff of offshore teams.

4-Highly Effective

3-Very Effective

2-Effective

1-Slightly Effective

0-Not Effective

2. Use of oral communication or no documentation on projects to enable knowledge transfer to new staff of offshore teams.

4-Highly Effective

3-Very Effective

2-Effective

1-Slightly Effective

0-Not Effective

3. Use of light documentation on projects to enable knowledge transfer to new staff of offshore teams.
4-Highly Effective
3-Very Effective
2-Effective
1-Slightly Effective
0-Not Effective

4. Additional comments regarding staff turnover risk in offshore outsourcing?

Next set of questions will focus generally on agile methodologies and offshore outsourcing.

\section{Other Questions}

1. How do you address code sharing on projects of offshore teams?

2. How does development staff of your offshore teams communicate on projects on offshore sites?

3. How do you manage your offshore teams?

Thank you for completing the questionnaire. 